\title{
RCC in cross ectopic kidney: a challenging diagnosis and management
}

\author{
Ahmad Alfaseh, ${ }^{1}$ Amro llaiwy ${ }^{2}$
}

'Urology Department, Kidney Surgical Hospital, Damascus, Syrian Arab Republic ${ }^{2}$ University of Miami Miller School of Medicine at Holy Cross Hospital, Fort Lauderdale, Florida, USA

\section{Correspondence to} Dr Amro llaiwy, amroilaiwy@gmail.com

Accepted 24 September 2018

\section{DESCRIPTION}

A 57-year-old woman with a 5-month history of left-upper quadrant (LUQ) abdominal pain was referred after a retroperitoneal mass was discovered on CT scan of the abdomen and pelvis. Clinical history revealed mild LUQ abdominal pain over the course of 5 months, associated with anorexia, unintended weight loss and several episodes of painless gross haematuria. Physical examination was positive for an ill-defined mass in the LUQ extending to the umbilical region. Routine laboratory tests did not reveal abnormal findings except for microscopic haematuria. CT scan images revealed a left cross ectopic kidney fusing laterally with the lower pole of right kidney in addition to a mass measuring $7.5 \times 8.5 \mathrm{~cm}$ emerging from the ectopic kidney. The mass extended to the left flank crossing the abdominal aorta and passing behind the inferior mesenteric artery. This structure mimicked a horseshoe kidney (figures 1 and 2). Retrograde pyelography confirmed the presence of cross ectopic left kidney with a mild hydronephrosis without evidence of ureter obstruction (figure 3). Partial nephrectomy was performed through a left subcostal transperitoneal approach. Pathology confirmed the diagnosis of papillary renal cell carcinoma (RCC). Postoperative course was complicated by mild urinary extravasation which was successfully managed by the placement of double J (DJ) catheters (figure 4).

Renal ectopia is a developmental renal anomaly characterised by abnormal anatomical location of one or both of the kidneys. Crossed ectopia is characterised by the ureter of the ectopic kidney

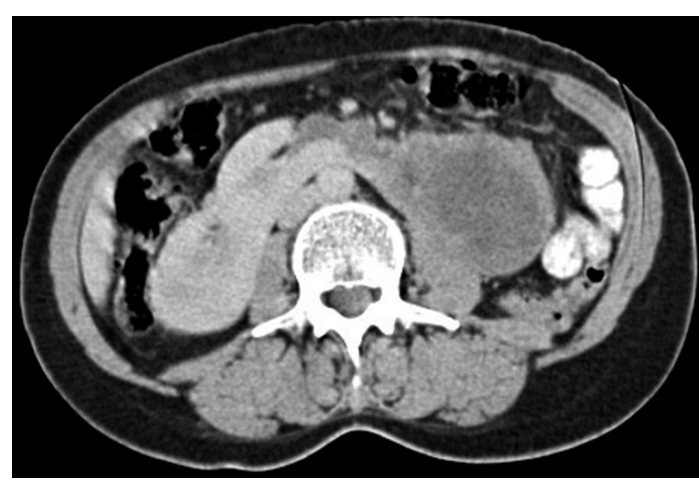

Figure 1 CT scan of the abdomen and pelvis with intravenous contrast demonstrates an axial view of left cross ectopic kidney with a mass extending to the left paravertebral region and fusing with the right kidney.

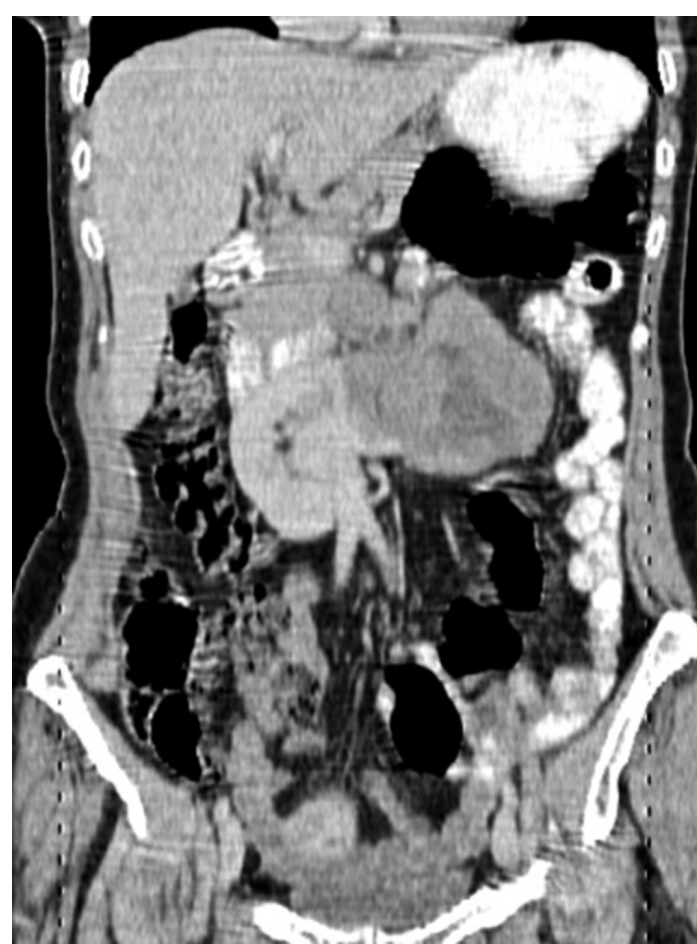

Figure 2 CT scan of the abdomen and pelvis with intravenous contrast demonstrates a coronal view of left cross ectopic kidney with a mass extending to the left paravertebral region and fusing with the right kidney.

crossing the midline before entering the bladder on the expected side. ${ }^{12}$ Cross fused renal ectopia is a rare anomaly with a mild male predominance. Most crossed ectopias are associated with fusion and left to right cross-over. ${ }^{2}$ Embryologically, this anomaly

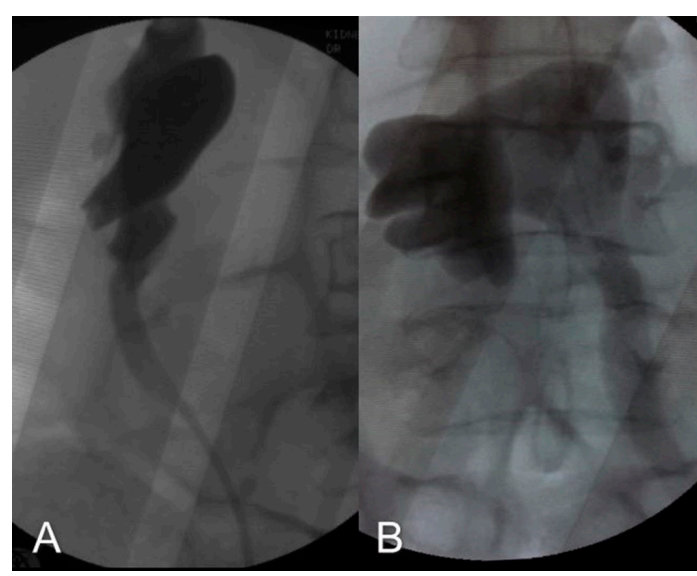

Figure 3 Retrograde pyelography shows (A) normal right kidney, (B) left hydronephrotic cross ectopic kidney. 


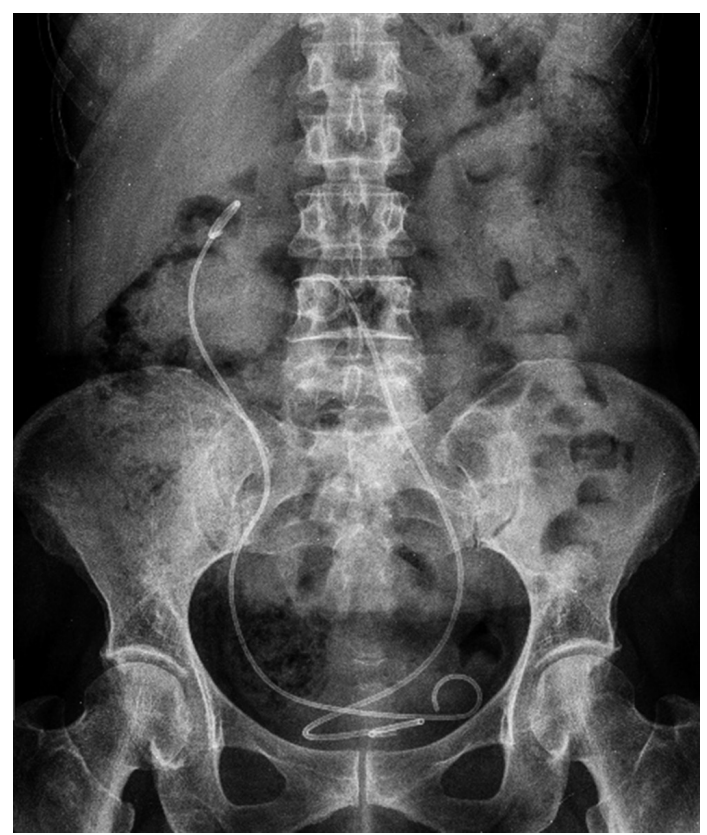

Figure 4 Abdominal X-ray demonstrates double J (DJ) catheters placed in both ureters. Left DJ catheter crosses the midline to the ectopic kidney.

occurs in the first trimester as a result of an abnormal development of the ureteric bud and metanephric blastema between 4 and 8 weeks' gestation. Mechanism involves arrest during kidney's migration, migration beyond normal limit, metanephric ectopia, contralateral metanephros induced by wandering ureteric bud or duplex Wolffian ducts. While most patients are asymptomatic, ectopic kidneys carry increased risk of urinary calculus formation and hydronephrosis. ${ }^{3}$

Accompanying malignancies have been reported in only few cases in the literature. RCC is the most common type of neoplasm associated with this anomaly. Incidence and prognostic factors of RCC in ectopic kidney are similar to what has been described in the general population. ${ }^{4}$ Due to unpredictable anatomy, preoperative imaging and ureteral stenting may be helpful in order to avoid significant surgical complications including haemorrhage and ureteral injury. Both traditional and Doppler ultrasound are considered the diagnostic methods of choice for both initial diagnosis and preoperative vascular evaluation. Tomography scan and MRI can also provide additional information preoperatively. ${ }^{5}$ While several surgical approaches have been described for renal fusion abnormalities, transperitoneal approach provides the optimal exposure of the anomalous anatomy allowing for early vasculature control and improved opportunity for nephron sparing. ${ }^{6}$

\section{Learning points}

- Renal ectopia is a developmental anomaly characterised by abnormal anatomical location of one or both of the kidneys.

- Diagnosing neoplasms in renal ectopia can be challenging and might mimic radiologically and clinically other renal anomalies, including horseshoe kidney.

- Although most patients remain asymptomatic, ectopic kidneys carry increased risk of urinary calculus formation as well as hydronephrosis.

- Preoperative vascular evaluation combined with transperitoneal approach save time and decrease risk of surgical complications.

Contributors AA: conception and design of this report, acquisition of data as well as drafting the manuscript. Al: drafting the report as well as critically revising it. Both coauthors approve this manuscript for final publication.

Funding The authors have not declared a specific grant for this research from any funding agency in the public, commercial or not-for-profit sectors.

Competing interests None declared.

Patient consent Obtained.

Provenance and peer review Not commissioned; externally peer reviewed.

\section{REFERENCES}

1 Shapiro E, Bauer SB, Chow JS. Anomalies of the upper urinary tract. Campbell-Walsh Urology 2012;4:3145.

2 Abeshouse BS, Bhisitkul I. Crossed renal ectopia with and without fusion. Urol Int 1959:9:63-91.

3. Boyan $N$, Kubat $H$, Uzum A. Crossed renal ectopia with fusion: report of two patients. Clin Anat 2007;20:699-702.

4 Cakmak 0, Isoglu CS, Peker EA, et al. Renal cell carcinoma in patient with crossed fused renal ectopia. Arch Ital Urol Androl 2016;87:330-1.

5 Mudoni A, Caccetta F, Caroppo M, et al. Crossed fused renal ectopia: case report and review of the literature. J Ultrasound 2017;20:333-7.

6 Davis CM, Rao MV, Flanigan RC, et al. Renal cell carcinoma in two patients with crossed fused ectopic kidneys. Urol Int 2008;81:370-2.

Copyright 2018 BMJ Publishing Group. All rights reserved. For permission to reuse any of this content visit

http://group.bmj.com/group/rights-licensing/permissions.

BMJ Case Report Fellows may re-use this article for personal use and teaching without any further permission.

Become a Fellow of BMJ Case Reports today and you can:

- Submit as many cases as you like

- Enjoy fast sympathetic peer review and rapid publication of accepted articles

- Access all the published articles

- Re-use any of the published material for personal use and teaching without further permission

For information on Institutional Fellowships contact consortiasales@bmjgroup.com

Visit casereports.bmj.com for more articles like this and to become a Fellow 